\title{
Magnitude and Determinants of Uncontrolled Blood Pressure Among Adult Hypertensive Patients on Follow-Up at Nekemte Referral Hospital, Western Ethiopia
}

This article was published in the following Dove Press journal:

Integrated Blood Pressure Control

\author{
Ginenus Fekadu (DD \\ Abdi Adamu ${ }^{2}$ \\ Mohammed Gebre (ID) \\ Busha Gamachu' \\ Firomsa Bekele ${ }^{3}$ \\ Muktar Abadiga ${ }^{4}$ \\ Getu Mosisa ${ }^{4}$ \\ Adugna Oluma ${ }^{4}$ \\ 'Clinical Pharmacy Unit, Department of \\ Pharmacy, Institute of Health Sciences, \\ Wollega University, Nekemte, Ethiopa; \\ ${ }^{2}$ Shanan Gibe Hospital, Jimma, Oromia \\ Regional State, Ethiopa; ${ }^{3}$ Department of \\ Pharmacy, College of Health Sciences, \\ Mettu University, Mettu, Ethiopa; \\ ${ }^{4}$ Department of Nursing, Institute of \\ Health Sciences, Wollega University, \\ Nekemte, Ethiopa
}

Background: Hypertension is the leading cause of morbidity and mortality among noncommunicable diseases. The rate of blood pressure (BP) control among hypertensive patients is poor and the reasons for poor control of BP remain poorly understood globally. Therefore, this study aimed to assess the magnitude and determinants of uncontrolled blood pressure among adult hypertensive patients on follow-up at Nekemte referral hospital (NRH).

Methods: A hospital-based cross-sectional study was conducted from February to April 2018 at NRH. BP control status was determined by the average consecutive BP recordings across the 3 months. The data was entered and analyzed using SPSS version 20.0 and p-value $<0.05$ was considered statistically significant.

Results: Out of 297 study participants included, the majority were females, 181 (60.9\%), and the mean age of the patients was $59.4 \pm 10.4$ years. About half, 137 (46.12\%), of the patients had at least one comorbidity and the most common class of anti-hypertensive medication was angiotensin-converting enzyme inhibitors $(88.2 \%)$. The mean of systolic blood pressure was $132.41 \pm 15.61 \mathrm{mmHg}$, while the mean of diastolic blood pressure was $84.37 \pm 9.32 \mathrm{mmHg}$. The proportion of participants with optimally controlled BP was $63.6 \%$ and $36 \%$ were adherent to their medications. Male sex (Adjusted Odd Ratio [AOR]: 1.89, 95\% CI: $1.09-4.84)$, illiteracy $(\mathrm{AOR}=1.56,95 \% \mathrm{CI}: 1.22-6.78)$, duration of hypertension diagnosis $>10$ years $(\mathrm{AOR}=2.01,95 \% \mathrm{CI}: 1.04-16.11)$, non-adherence $(\mathrm{AOR}=3.14,95 \%$ CI: $1.35-10.76)$ and lack of physical exercise $(\mathrm{AOR}=2.8,95 \% \mathrm{CI}: 1.16-6.74)$ were positively associated with uncontrolled BP status. Whereas age older than 55 years $(\mathrm{AOR}=$ 0.38, 95\% CI: 0.11-0.92) was negatively associated with uncontrolled BP.

Conclusion: BP control was relatively achieved in about two-third of pharmacologically treated patients. We recommend better health education and care of patients to improve the rate of $\mathrm{BP}$ control status.

Keywords: blood pressure, blood pressure control, hypertension, hypertensive patients, Ethiopia

\section{Introduction}

Hypertension (HTN), being the root cause of many of the body system and organs failure, remains an important global concern and public health problem. ${ }^{1-4}$ It is usually asymptomatic and chronic disorder needing lifelong treatment. ${ }^{5,6}$ HTN affects around one billion individuals globally and the burden is projected to increase by $29 \%$ to reach 1.56 billion by $2025 .^{1,5-8}$ It is one of the major, prevalent but modifiable risk factors,

\section{Correspondence: Ginenus Fekadu}

Clinical Pharmacy Unit, Department of Pharmacy, Institute of Health Sciences, Wollega University, Nekemte, Oromia, Ethiopia

Tel $+25|-9| 7|37| 45$

$\mathrm{Fax}+251-576617980$

Email take828pharm@gmail.com 
especially among patients with established cardiovascular disease (CVD) and cerebrovascular accidents. ${ }^{2,9,10}$ As a result, HTN is the leading cause of morbidity and mortality among non-communicable diseases ${ }^{11-15}$ and ranks third as a cause of disability-adjusted life-year causing about 7.1 million premature deaths each year. ${ }^{11}$ Additionally, the complications of HTN account for 9.4 million deaths worldwide every year. ${ }^{6}$ Still, the incidence of heart failure and mortality from cardiovascular complications of hypertension is high among patients with uncontrolled blood pressure (UBP). ${ }^{16}$

If left uncontrolled, HTN causes stroke, heart failure, dementia, coronary heart disease, peripheral vascular disease, renal impairment, retinal hemorrhage and blindness imposing severe financial and service burdens on health care systems. ${ }^{9,11,17-19}$ There is a close relationship between blood pressure (BP) levels and the risk of cardiovascular events, strokes and kidney disease. Above 115/75 mm Hg, for each increase of $20 \mathrm{~mm} \mathrm{Hg}$ in systolic blood pressure (SBP) or $10 \mathrm{~mm} \mathrm{Hg}$ in diastolic blood pressure (DBP), the risk of major cardiovascular and stroke events doubles. ${ }^{19,20}$

HTN is a long-term condition posing formidable challenges to the health care system in developed and developing countries. ${ }^{8,14}$ But it has become an important chronic noncommunicable disease (NCD) with increasing trends in developing countries. ${ }^{16}$ Prevalent HTN was lower in highthan low-middle-income countries (LMICs), but awareness, treatment, and control were substantially lower in LMICs. ${ }^{14}$ With this, more than $80 \%$ of deaths from HTN and associated CVDs occur in developing countries. ${ }^{6,21}$ Even the prevalence of HTN has been increasing at an alarming rate among developing nations, especially in the African region. ${ }^{15,22}$

The prevalence of HTN in Sub-Saharan Africa (SSA) has attained epidemic proportions likely due to the epidemiological transition and lifestyle modification with the adoption of western lifestyles. ${ }^{23,24}$ In SSA, an estimated 74.7 million individuals are hypertensive and by the year 2025 , the number of hypertensive individuals is projected to increase by $68 \%$ to 125.5 million individuals. ${ }^{25}$ In Ethiopia, NCD is estimated to account for $30 \%$ of total annual deaths of which $9 \%$ is attributed to CVD. ${ }^{26}$ The prevention and control of HTN have not received due attention in Ethiopia compared with other computing diseases like HIV/AIDS, tuberculosis and malaria. ${ }^{3}$

Controlling BP is needed to reduce the morbidity and mortality of CVD. ${ }^{10,15,22}$ Even the complications of HTN can be delayed with good BP control. ${ }^{22}$ Several lifestyle interventions have been shown to reduce BP. ${ }^{8}$ Despite the availability and improvement in diagnostic and therapeutic interventions, large segments of the hypertensive population in the world are either untreated or inadequately treated. $8,16,20$

The rate of BP control among hypertensive patients is poor and the causes for poor control of BP remain poorly understood globally. ${ }^{8,21}$ Control may remain poor as a result of limited resources, the deficit of trained professionals, poor adherence to medication as well as an inappropriate choice of medications. ${ }^{2}$ Improvement of its management to reduce adverse cardiovascular outcomes will require an understanding of the patient, disease and treatment factors associated with UBP. ${ }^{24}$ Controlling BP in people with HTN to reduce cardiovascular morbidity and mortality is a major challenge public health problems in many LMICs including Ethiopia. ${ }^{15}$

Limited information exists on BP control factors and adherence to antihypertensive drug therapy in developing countries. ${ }^{1,27}$ Current disease estimates for SSA are based on limited data and hypertension control assumes a relatively low priority and little experience exists in implementing sustainable and successful programs. ${ }^{3}$ Although several studies have shown the prevalence and factors associated with HTN in Ethiopia, there is limited information about the magnitude and determinants of blood control status in Ethiopia. ${ }^{3,4,8,15}$ The lack of adequate studies on HTN significantly affects HTN management and the care of hypertensive patients in Ethiopia. ${ }^{21}$

Improvement in the management and control of HTN will require an understanding of the factors that affect BP control. ${ }^{8}$ So, knowing the BP control status of hypertensive patients is very important for policymakers and clinicians responsible for designing appropriate strategies for better management of hypertensive patients. ${ }^{16}$ Therefore, this study aimed to assess the magnitude and determinants of uncontrolled blood pressure among adult hypertensive patients on follow-up at Nekemte referral hospital (NRH).

\section{Methods and Participants Study Setting, Study Design and Period}

The study was conducted at NRH, located at $331 \mathrm{~km}$ from west of Addis Ababa. NRH has more than 200 beds and provides diagnostic and treatment services for about 100,000 populations per year. The medical wards of NRH have 37 beds and an average of 215 new admissions per month. A hospital-based cross-sectional study was conducted from February- April 2018. 


\section{Eligibility Criteria}

All hypertensive patients aged 18 years and older who were on pharmacologic therapy for at least 6 months before the study period and were attending the medicine outpatient department for follow-up during the study period were included in the study. However, pregnant mothers, newly diagnosed patients, refuse to participate in the study, patients with hypertensive urgency or emergency, patients with cognitive impairment, seriously ill patients that made it impossible to conduct a reliable interview and patients with incomplete medical records such as demographics and BP were excluded. A total of 297 hypertensive patients fulfilling eligibility criteria who were on antihypertensive medications were enrolled conveniently.

\section{Study Variables \\ Dependent Variable \\ - BP control status}

\section{Independent Variables}

- Baseline characteristics (age, sex, body mass index, monthly income, education level, marital status, occupation, ethnicity, and residence)

- Disease-related factors (family history of hypertension, frequency of follow up, frequency of BP measurement, presence of co-morbidity and duration of the disease)

- Drug-related factors (the type of antihypertensive drug/s, number of antihypertensive drug/s, side effect, and the dose of medications)

- Behavioral factors (adherence to medication, smoking status, alcohol drinking status, physical exercise and amount of salt in the food)

\section{Data Collection Process and Quality Control}

A pretested data abstraction tool adopted from the World Health Organization (WHO) stepwise approach to surveillance of NCDs and chronic disease risk factors ${ }^{28,29}$ was used to collect data. One medical doctor and two nurses collected data from both primary and secondary sources (patient interviews and record reviews). A medical records review was performed and a data abstraction format was completed for each eligible patient to obtain co-morbid condition/s, BP measurements and type/s of antihypertensive medication/s. Patients were interviewed to obtain socio-demographic, disease-related, lifestyle-related and drug-related information as well as assess their adherence to medication.

To maintain the validity of the data collection tool, the questionnaire was first prepared in English and translated into the local language (Amharic and Afan Oromo) and finally back to English to maintain its consistency. The pretest was done on $5 \%$ of the total sample at Wollega University referral hospital to ensure the quality and agreement of the data abstraction format and the structured questionnaire with the need for the study. Any error found during the process of the pretest was corrected and modification was made into the final version of the data abstraction tool. Data collectors were trained for two days before the process of data collection. Collected data was checked daily for completeness and consistency on the spot during data collection time.

\section{BP Measurement Procedure and Hypertension Control Status}

BP was measured by a physician who followed hypertensive patients during their office visits. BP recordings in the charts of adult hypertensive patients for the last 6 months were reviewed. The last BP was measured by data collectors using a pretested standard mercury sphygmomanometer BP cuff with the appropriate cuff size that covered two-thirds of the upper arm, while the patient was in a sitting position, rested for at least 5 minutes and consumed no cigarettes or caffeine 30 minutes before the measurement. Excess clothing that might affect the BP cuff has been removed. Patients were kept calm during the BP measurement. The BP cuff was inflated enough to stop blood flow until no sounds were heard through the stethoscope. Then the cuff deflates slowly to measure the systolic and diastolic BP. Two consecutive measurements were taken in a minimum interval of 5 minutes, and the mean was considered for data analysis. ${ }^{30-32}$

Hypertensive patients were further dichotomized into controlled and uncontrolled BP groups based upon achievement of blood pressure goals as per the eighth joint national committee (JNC 8) recommendations. ${ }^{9,15,16,31}$ Patients were classified as having controlled BP if BP readings $<140 / 90$ $\mathrm{mmHg}$ for all adults $\geq 18$ years old and $<150 / 90$ for adults aged $\geq 60$ years. Uncontrolled if BP $\geq 150 / 90 \mathrm{mmHg}$ in hypertensive patients aged 60 or older, or $\mathrm{BP} \geq 140 / 90$ $\mathrm{mmHg}$ in hypertensive patients aged less than 60 years and all ages of hypertensive patients with diabetes or chronic kidney disease. Then, the BP recordings at each 
visit were used as a dependent variable, but the prevalence of controlled BP was determined by the average consecutive recent $\mathrm{BP}$ recordings across the 3 months.

\section{Adherence to Antihypertensive Treatment}

We used Hill-Bone Compliance to High Blood Pressure Therapy Scale (HB-HBP), a measure of reviewing patient's medication-taking behavior and barriers to adherence. This scale has been suggested as suitable for use in studies specific to hypertension in the black population. This brief instrument provides a simple method for clinicians in various settings to assess patients' self-reported adherence and to plan appropriate interventions.

HB-HBP is a 14-item scale that assesses patient behaviors for three important behavioral domains of high blood pressure treatment (i.e. the three sub-scales): appointment keeping (3-items), diet (e.g. reduced sodium intake) (2-items) and medication adherence (9-items). Each item is a four-point Likert type scale (none of the time, some of the time, most of the time and all of the time). ${ }^{33-36}$ For this study purpose, we selected the 9-item medication-taking subscale. The total scores on this subscale range from 9 to 36 with higher scores reflecting poorer adherence to antihypertensive drug therapy. These 9 item adherence scale includes questions like asking how often patients forgot to take their hypertension medication, decide not to take, leave the dispensary without obtaining prescribed pills, run out of hypertension pills, skip of medicine before going to the clinic, miss taking of medicines feeling better, sick or being careless and take someone else's hypertension pills. The median split was used and dichotomized into two groups $1=$ Adherent to the treatment and $0=$ Non-adherent to the medication.

\section{Behavioral and Other Factors}

A patient who smokes at least one cigarette per day during the study period was considered as a smoker. ${ }^{16}$ Male patients who drink more than 2 units of alcohol/day and female patients who drink more than 1 unit of alcohol/day were considered as alcohol consumers. ${ }^{16}$ Body Mass Index (BMI) was calculated as weight in kilograms divided by height in square meters and interpreted as underweight $\left(\mathrm{BMI}<18.59 \mathrm{~kg} / \mathrm{m}^{2}\right)$, normal weight (18.5-24.99 kg/m²), overweight (25.0-29.99 kg/m2) and obese $\left(\geq 30.09 \mathrm{~kg} / \mathrm{m}^{2}\right){ }^{21,37}$

Physical activity was assessed by asking the number of minutes per day and the number of days per week a patient spent doing physical activity. The participants were classified as physically active if they perform a physical exercise for at least 30 minutes per day for at least 5 days per week ( $\geq 150$ minutes per week), otherwise, they were classified as physically inactive..$^{9,21,27,38}$ This physical exercise includes work or sports that involve a moderate-intensity activity that causes small increases in breathing or heart rate, such as brisk walking, carrying light loads, cycling, swimming, volleyball, dancing, farming, gardening, and house working. ${ }^{16,21}$

\section{Data Processing and Analysis}

The data were entered and analyzed using Statistical Package for the Social Sciences (SPSS) version 20.0. Descriptive statistics including frequency, mean and standard deviation (SD) were used to summarize study variables and evaluate the distribution of responses. Logistic regression was used to determine factors associated with BP control status. Both the crude odds ratio (COR) and adjusted odds ratio (AOR) with the corresponding 95\% confidence interval $(\mathrm{CI})$ were calculated to determine the strength of the association between dependent and independent variables. Variables with p-values $\leq 0.25$ in the bivariate analysis were fitted in the multivariable logistic regression for controlling possible effects of confounders and a p-value of less than 0.05 was considered statistically significant.

\section{Results}

\section{Socio-Demographic Characteristics}

A total of 330 participants were included in this study with a response rate of 297 (90\%). The majority of study participants were females $181(60.9 \%)$. The mean age of the patients was $59.4 \pm 10.4$ years and the majority, 112 $(37.7 \%)$ were between the age category of 45-54 years. About 247 (83.2\%) were married and 96 (32.3\%) attended primary school. Regarding occupation, 88 (29.6\%) were farmers followed by housewives $83(27.9 \%)$. The majority of them, $183(61.6 \%)$ were protestant in religion and 113 (38\%) had a monthly income of less than 500 Ethiopian birr (Table 1).

\section{Anthropometric and Clinical Characteristics}

The mean BMI of the patients was $22.61 \pm 4.22 \mathrm{~kg} / \mathrm{m}^{2}$. Of the total study participants, $230(77.4 \%)$ had normal body weight and $16(5.4 \%)$ were overweight. The clinical 
Table I Socio-Demographic Characteristics of Hypertensive Patients on Follow-Up at NRH, 2018

\begin{tabular}{|c|c|c|c|}
\hline Variables & Category & Frequency(n) & $\begin{array}{l}\text { Percent } \\
\text { (\%) }\end{array}$ \\
\hline Sex & $\begin{array}{l}\text { Male } \\
\text { Female }\end{array}$ & $\begin{array}{l}116 \\
181\end{array}$ & $\begin{array}{l}39.1 \\
60.9\end{array}$ \\
\hline Age (years) & $\begin{array}{l}18-24 \\
25-34 \\
35-44 \\
45-54 \\
\geq 55\end{array}$ & $\begin{array}{l}2 \\
22 \\
69 \\
112 \\
92\end{array}$ & \begin{tabular}{l|}
0.7 \\
7.4 \\
23.2 \\
37.7 \\
31.0
\end{tabular} \\
\hline Ethnicity & $\begin{array}{l}\text { Oromo } \\
\text { Amhara } \\
\text { Gurage } \\
\text { Tigre }\end{array}$ & $\begin{array}{l}273 \\
20 \\
3 \\
1\end{array}$ & $\begin{array}{l}91.9 \\
6.7 \\
1.0 \\
0.3\end{array}$ \\
\hline Marital status & $\begin{array}{l}\text { Married } \\
\text { Widowed } \\
\text { Single } \\
\text { Divorced }\end{array}$ & $\begin{array}{l}247 \\
35 \\
8 \\
7\end{array}$ & $\begin{array}{l}83.2 \\
11.8 \\
2.7 \\
2.4\end{array}$ \\
\hline Religion & $\begin{array}{l}\text { Protestant } \\
\text { Orthodox } \\
\text { Muslim } \\
\text { Catholic }\end{array}$ & $\begin{array}{l}183 \\
91 \\
19 \\
4\end{array}$ & $\begin{array}{l}61.6 \\
30.6 \\
6.4 \\
1.3\end{array}$ \\
\hline $\begin{array}{l}\text { Educational } \\
\text { status }\end{array}$ & $\begin{array}{l}\text { Illiterate } \\
\text { Primary education } \\
\text { Secondary } \\
\text { education } \\
\text { College/university } \\
\text { or above }\end{array}$ & $\begin{array}{l}72 \\
96 \\
55 \\
74\end{array}$ & $\begin{array}{l}24.2 \\
32.3 \\
18.5 \\
\\
24.9\end{array}$ \\
\hline Work status & $\begin{array}{l}\text { Farmer } \\
\text { Housewife } \\
\text { Government } \\
\text { employee } \\
\text { Private business } \\
\text { Retired } \\
\text { Daily laborer } \\
\text { Unemployed } \\
\text { Others* }\end{array}$ & $\begin{array}{l}88 \\
83 \\
62 \\
\\
22 \\
16 \\
11 \\
7 \\
8\end{array}$ & $\begin{array}{l}29.6 \\
27.9 \\
20.9 \\
\\
7.4 \\
5.4 \\
3.7 \\
2.4 \\
2.7\end{array}$ \\
\hline $\begin{array}{l}\text { Monthly } \\
\text { income (ETB) }\end{array}$ & $\begin{array}{l}<500 \\
500-1000 \\
100 I-2000 \\
>2000\end{array}$ & $\begin{array}{l}113 \\
59 \\
33 \\
92\end{array}$ & $\begin{array}{l}38.0 \\
19.9 \\
11.1 \\
31.0\end{array}$ \\
\hline
\end{tabular}

Notes: *Construction, Guard, Dependent, No job.

Abbreviations: ETB, Ethiopian birr; NRH, Nekemte Referral Hospital.

characteristics of patients showed that 73 (24\%) participants had a family history of HTN and $287(96.6 \%)$ had a monthly follow up. About half, 137 (46.12\%), of the participants, had at least one co-morbidity. From these, 82 $(27.6 \%)$ had diabetic and $40(13.6 \%)$ had heart failure as
Table 2 Anthropometric and Clinical Characteristics of Hypertensive Patients on Follow-Up at NRH, 2018

\begin{tabular}{|c|c|c|c|}
\hline Variable & Category & $\begin{array}{l}\text { Frequency } \\
\text { (n) }\end{array}$ & $\begin{array}{l}\text { Percent } \\
(\%)\end{array}$ \\
\hline $\begin{array}{l}\text { Body mass } \\
\text { index }\left(\mathrm{kg} / \mathrm{m}^{2}\right)\end{array}$ & $\begin{array}{l}<18.5 \\
18.5-24.9 \\
25-29.9 \\
\geq 30\end{array}$ & $\begin{array}{l}13 \\
230 \\
38 \\
16\end{array}$ & \begin{tabular}{l|}
4.4 \\
77.4 \\
12.8 \\
5.4
\end{tabular} \\
\hline $\begin{array}{l}\text { Family history } \\
\text { of hypertension }\end{array}$ & $\begin{array}{l}\text { Yes } \\
\text { No }\end{array}$ & $\begin{array}{l}73 \\
224\end{array}$ & $\begin{array}{l}24.6 \\
75.4\end{array}$ \\
\hline $\begin{array}{l}\text { Duration of } \\
\text { hypertension } \\
\text { diagnosis } \\
\text { (years) }\end{array}$ & $\begin{array}{l}<5 \\
5-10 \\
>10\end{array}$ & $\begin{array}{l}125 \\
101 \\
71\end{array}$ & $\begin{array}{l}42.1 \\
34.0 \\
23.9\end{array}$ \\
\hline $\begin{array}{l}\text { Frequency of } \\
\text { follow-up }\end{array}$ & $\begin{array}{l}\text { Monthly } \\
\text { Every two months }\end{array}$ & $\begin{array}{l}287 \\
10\end{array}$ & $\begin{array}{l}96.6 \\
3.4\end{array}$ \\
\hline $\begin{array}{l}\text { Frequency of } \mathrm{BP} \\
\text { measurement }\end{array}$ & $\begin{array}{l}\text { Monthly } \\
\text { Weekly } \\
\text { Every two weeks } \\
\text { Every two months } \\
\text { Others (irregularly) }\end{array}$ & $\begin{array}{l}186 \\
35 \\
51 \\
4 \\
21\end{array}$ & $\begin{array}{l}62.6 \\
11.8 \\
17.2 \\
1.3 \\
7.1\end{array}$ \\
\hline $\begin{array}{l}\text { Co-morbid } \\
\text { condition }\end{array}$ & $\begin{array}{l}\text { Diabetes } \\
\text { Heart failure } \\
\text { Chronic Kidney } \\
\text { disease } \\
\text { Myocardial infarction } \\
\text { Others* }\end{array}$ & $\begin{array}{l}82 \\
40 \\
3 \\
2 \\
10\end{array}$ & $\begin{array}{l}27.6 \\
13.5 \\
1.0 \\
0.7 \\
3.4\end{array}$ \\
\hline
\end{tabular}

Notes: *Musculoskeletal disease, Gout, Migraine, Ischemic heart disease, asthma. Abbreviations: BP, blood pressure; NRH, Nekemte Referral Hospital.

a comorbid disease. The mean duration of time since the diagnosis of HTN was $6.43 \pm 3.721$ years (Table 2).

\section{Antihypertensive Therapy and Life Style Related Factors}

Among the study participants, only 3(1\%) were current smokers and $50(16.8 \%)$ participants reported the use of alcohol. Regarding exercise, about 33 (11.1\%) of participants reported performing physical exercise. Among the study participants, $219(73.7 \%)$ reported as they reduced salt in their food. The most common class of anti-hypertensive medication was angiotensin converting-enzyme inhibitors (ACEIs) (88.2\%) followed by thiazide diuretics (45.2\%). About half, 150 $(50.5 \%)$ of the patients were on two drugs combination. ACEIs (enalapril) was the most common monotherapy used $113(38.0 \%)$ while the most common combination drug therapy was the association of a diuretic (hydrochlorothiazide) and ACEIs (enalapril) (36.7\%). About 123 (41.4\%) of the 
patients got their medication free of charge and 131 (44.1\%) got by self-sponsored (out pocket expense). The majority, 125 (42.1\%) of the patients were on antihypertensive treatment for less than 5 years. The mean period for antihypertensive drug therapy was $3.83 \pm 5.91$. About 91 (30.6\%) reported the experience of at least one side effect from the medication/s. Headache and weakness were the major experienced side effects due to medications (Table 3).

\section{Blood Pressure Control and Adherence to Antihypertensive Medications}

The mean of SBP was $132.41 \pm 15.61 \mathrm{mmHg}$ while the mean of DBP was $84.37 \pm 9.32 \mathrm{mmHg}$. Based on the mean of the last three blood pressure measurements, 189 $(63.6 \%)$ of the patients had a controlled BP. The 9 items HBMA rate were added up to get sum index with a distribution ranging from 9 to 29 with mean 15.86 \pm 2.61 . The median split was used (15.8) to dichotomize into two groups: $1=$ Adherent to the treatment, $0=$ Non- adherent to the treatment to the prescribed medication which was 9-15 and 16-36, respectively. More than one third $(36 \%)$ of the study participants were found to be adherent while $64 \%$ of them were not adherent to their medications according to a self-reported HBMA rate.

\section{Determinants of Uncontrolled Blood Pressure}

In bivariate analysis; sex, age, marital status, educational status, duration of diagnosis, source of medication, adherence, comorbidity, experienced side effect, physical exercise and frequency of follow up were associated with BP control status at $\mathrm{p}$-value $<0.25$. On multivariable logistic regression analysis; sex, age, educational status, duration of diagnosis, medication adherence and physical exercise were significantly associated with BP control status. In this study, male patients were about two times more likely to have UBP compared to female patients (AOR: 1.89, 95\% CI: $1.09-4.84, \mathrm{p}=0.005)$. UBP among illiterate patients

Table 3 Antihypertensive Therapy and Lifestyle Related Factors Among Patients on Follow Up at NRH, 2018

\begin{tabular}{|c|c|c|c|c|}
\hline \multicolumn{2}{|l|}{ Variables } & Category & Frequency & Percent \\
\hline \multirow{3}{*}{\multicolumn{2}{|c|}{ Duration of therapy (years) }} & & 125 & 42.1 \\
\hline & & & & \\
\hline & & $\geq 10$ & 71 & 23.9 \\
\hline \multirow[t]{9}{*}{ Medications } & Monotherapy & Enalapril & 113 & 38.0 \\
\hline & $(n=147)$ & Hydrochlorothiazide & 23 & 7.7 \\
\hline & & Nifedepine & 11 & 3.7 \\
\hline & Drug Combination & Hydrochlorothiazide+ Enalapril & 109 & 36.7 \\
\hline & $(n=150)$ & Hydrochlorothiazide+ Nifedepine & 2 & 0.7 \\
\hline & & Hydrochlorothiazide+ Propranolol & 1 & 0.3 \\
\hline & & Enalapril + Nifedepine & 33 & II.I \\
\hline & & Enalapril + Atenolol & 4 & 1.3 \\
\hline & & Enalapril + Propranolol & I & 0.3 \\
\hline \multirow{3}{*}{\multicolumn{2}{|c|}{ Source of medication }} & Self-sponsored & $|3|$ & 44.1 \\
\hline & & Free of charge & 123 & $4 I .4$ \\
\hline & & By sponsorship & 43 & 14.5 \\
\hline \multirow{2}{*}{\multicolumn{2}{|c|}{ Side effect }} & Yes & 91 & 30.6 \\
\hline & & No & 206 & 69.4 \\
\hline \multirow{7}{*}{\multicolumn{2}{|c|}{$\begin{array}{l}\text { Experienced Side effect } \\
(n=91)\end{array}$}} & Weakness & 34 & 37.36 \\
\hline & & Headache & 24 & 26.37 \\
\hline & & Dry mouth & 14 & 15.38 \\
\hline & & Erectile dysfunction & 8 & 8.79 \\
\hline & & Gl complaint & 3 & 3.3 \\
\hline & & Cough & 3 & 3.3 \\
\hline & & Others* & 4 & 4.4 \\
\hline
\end{tabular}

Notes: *Others: Postural hypertension, Edema, Loss of appetite, Foot pain

Abbreviations: GI, gastro-intestinal; NRH, Nekemte Referral Hospital. 
was 1.5 times more likely than who had college and university education level $(\mathrm{AOR}=1.56,95 \% \mathrm{CI}: 1.22$ $6.78, \mathrm{p}=0.029$ ). Patients with age $\geq 55$ years were $62 \%$ $(\mathrm{AOR}=0.38,95 \% \mathrm{CI}: 0.11-0.92, \mathrm{p}=0.03)$ less likely to have UBP than those $<55$ years of age. Duration of hypertension diagnosis was also associated with UBP in that patients with a diagnosis longer than 10 years were 2 times more likely to have UBP than those with a diagnosis of $<5$ years $(\mathrm{AOR}=2.01,95 \% \mathrm{CI}: 1.04-16.11, \mathrm{p}=0.42)$. Additionally, non-adherent patients were about three times more likely to have UBP than adherents $(\mathrm{AOR}=$
3.14, 95\% CI: $1.35-10.76, p=0.032$ ). Finally, patients not involved in the physical exercise were about three times more likely to have UBP compared to those did involve in the physical exercise $(\mathrm{AOR}=2.8,95 \% \mathrm{CI}: 1.16-6.74$, $\mathrm{p}=0.02$ ) (Table 4).

\section{Discussion}

The study represents the analysis of factors that are associated with BP control status at NRH. The major finding of this study revealed that about two-thirds of the hypertensive patients on antihypertensive treatment had controlled

Table 4 Bivariate and Multivariable Logistic Regression Analysis of Factors Associated Blood Pressure Control Status Among Hypertensive Patients on Follow Up at NRH, 2018

\begin{tabular}{|c|c|c|c|c|c|c|}
\hline \multicolumn{2}{|l|}{ Characteristics } & \multicolumn{2}{|c|}{ Blood Pressure Control } & \multirow{3}{*}{$\begin{array}{l}\text { COR }(95 \% \mathrm{Cl}) \\
\mathrm{I} .7 \mathrm{I}(1.05-2.76)^{*}\end{array}$} & \multirow{3}{*}{$\begin{array}{l}\text { AOR }(95 \% \mathrm{Cl}) \\
1.89(1.09-4.84)^{* *}\end{array}$} & \multirow{3}{*}{$\begin{array}{l}\text { p-value } \\
0.005\end{array}$} \\
\hline & & \multirow{2}{*}{$\begin{array}{l}\text { Uncontrolled (\%) } \\
51(44 \%) \\
57(31.5 \%)\end{array}$} & \multirow{2}{*}{$\begin{array}{l}\text { Controlled (\%) } \\
65(56 \%) \\
124(68.5 \%)\end{array}$} & & & \\
\hline Sex & $\begin{array}{l}\text { Male } \\
\text { Female }\end{array}$ & & & & & \\
\hline Age (years) & $\begin{array}{l}\geq 55 \\
<55\end{array}$ & $\begin{array}{l}34(37 \%) \\
|3|(63.9 \%)\end{array}$ & $\begin{array}{l}58(63 \%) \\
74(36.1 \%)\end{array}$ & $\begin{array}{l}0.33(0.012-0.78)^{*} \\
1\end{array}$ & $0.38(0.11-0.92)^{* *}$ & 0.03 \\
\hline Marital status & $\begin{array}{l}\text { Widowed } \\
\text { Divorced } \\
\text { Married } \\
\text { Single }\end{array}$ & $\begin{array}{l}9(25.7 \%) \\
4(57.1 \%) \\
93(37.7 \%) \\
2(25 \%)\end{array}$ & $\begin{array}{l}26(74.3 \%) \\
3(42.9 \%) \\
154(62.3 \%) \\
6(75 \%)\end{array}$ & $\begin{array}{l}1.04(0.65-1.39)^{*} \\
4.0(1.28-18.27)^{*} \\
1.82(0.77-6.1) \\
I\end{array}$ & & \\
\hline Education level & $\begin{array}{l}\text { Illiterate } \\
\text { Primary education } \\
\text { Secondary education } \\
\text { College and university }\end{array}$ & $\begin{array}{l}26(36.1 \%) \\
37(38.5 \%) \\
19(34.5 \%) \\
26(35.1 \%)\end{array}$ & $\begin{array}{l}46(63.9 \%) \\
59(61.5 \%) \\
36(65.5 \%) \\
48(64.9 \%)\end{array}$ & $\begin{array}{l}\text { I.I }(0.98-4.7)^{*} \\
0.93(0.53-1.05) \\
0.96(0.68-3.4) \\
I\end{array}$ & $1.56(1.22-6.78)^{* *}$ & 0.029 \\
\hline $\begin{array}{l}\text { Frequency of follow } \\
\text { up }\end{array}$ & $\begin{array}{l}\text { Every two months } \\
\text { Monthly }\end{array}$ & $\begin{array}{l}6(60 \%) \\
107(37.3 \%)\end{array}$ & $\begin{array}{l}3(30 \%) \\
180(62.7)\end{array}$ & $\begin{array}{l}3.36(0.17-22.8)^{*} \\
1\end{array}$ & & \\
\hline Duration diagnosis & $\begin{array}{l}\geq 10 \text { years } \\
5-10 \text { years } \\
<5 \text { years }\end{array}$ & $\begin{array}{l}36(50.7 \%) \\
38(37.6 \%) \\
44(35.2 \%)\end{array}$ & $\begin{array}{l}35(49.3 \%) \\
63(62.4 \%) \\
81(64.8 \%)\end{array}$ & $\begin{array}{l}\text { I.89 }(0.8-11.79)^{*} \\
\text { I.II }(0.4 I-1.95) \\
\text { I }\end{array}$ & $2.01(1.04-16.11)^{* *}$ & 0.042 \\
\hline $\begin{array}{l}\text { Source of } \\
\text { medication }\end{array}$ & $\begin{array}{l}\text { Self - sponsored } \\
\text { By sponsorship } \\
\text { Free of charge }\end{array}$ & $\begin{array}{l}85(64.9 \%) \\
19(44.2 \%) \\
43(35 \%)\end{array}$ & $\begin{array}{l}46(35.1 \%) \\
24(55.8 \%) \\
80(65 \%)\end{array}$ & $\begin{array}{l}3.44(1.34-8.38)^{*} \\
1.47(0.6-1.68) \\
\text { I }\end{array}$ & & \\
\hline Adherence & $\begin{array}{l}\text { Non adherent } \\
\text { Adherent }\end{array}$ & $\begin{array}{l}126(66.3 \%) \\
44(41.1 \%)\end{array}$ & $\begin{array}{l}64(33.7 \%) \\
63(58.9 \%)\end{array}$ & $\begin{array}{l}2.82(0.4-9.18)^{*} \\
I\end{array}$ & $3.14(1.35-10.76)^{* *}$ & 0.032 \\
\hline $\begin{array}{l}\text { Experienced side } \\
\text { effects }\end{array}$ & $\begin{array}{l}\text { Yes } \\
\text { No }\end{array}$ & $\begin{array}{l}34(37.4) \\
74(35.9)\end{array}$ & $\begin{array}{l}57(62.6) \\
132(64.1)\end{array}$ & $\begin{array}{l}1.06(0.64-1.77)^{*} \\
\mathrm{I}\end{array}$ & & \\
\hline Comorbidity & $\begin{array}{l}\text { Yes } \\
\text { No }\end{array}$ & $\begin{array}{l}90(65.7 \%) \\
94(58.75 \%)\end{array}$ & $\begin{array}{l}47(34.3 \%) \\
66(41.25 \%)\end{array}$ & $\begin{array}{l}1.34(0.8-12.4 \mathrm{I})^{*} \\
\mathrm{I}\end{array}$ & & \\
\hline Physical exercise & $\begin{array}{l}\text { No } \\
\text { Yes }\end{array}$ & $\begin{array}{l}100(37.9) \\
8(24.2)\end{array}$ & $\begin{array}{l}164(62.1) \\
25(75.8)\end{array}$ & $\begin{array}{l}1.9(0.83-4.38)^{*} \\
1\end{array}$ & $2.8(1.16-6.74)^{* *}$ & 0.02 \\
\hline
\end{tabular}

Notes: *Significantly associated at P-value 0.25 ; **Significantly associated at $\mathrm{p}$-value 0.05 .

Abbreviations: AOR, Adjusted odds ratio; COR, Crude odds ratio; Cl, Confidence interval; NRH, Nekemte Referral Hospital. 
BP. The level of BP control found in this study $(63.6 \%)$ was relatively comparable with studies from health care in Chilean $(59.7 \%),{ }^{39}$ in USA at different levels of the health system (60\%), ${ }^{40}$ South Africa (57\%), ${ }^{41}$ Bhusal et al in India $(58.9 \%),{ }^{5}$ by Sandoval et al in Chile $(63.1 \%)^{27}$ and by Cordero et al in Spain $(55.4 \%){ }^{10}$ This close similarity in the level of BP control might be due to similarities in the eligibility criteria for the studies as only hypertensive patients on pharmacologic therapy were included. Additionally, a more aggressive strategy in the treatment of HTN (the use of combination antihypertensive agents) was common in most studies.

On the contrary, the level of BP control in this study was higher than the results obtained from hospital-based studies conducted by Shelley et al in USA (49.8\%), in six public primary care clinics of Malaysia (49.3\%), ${ }^{22}$ Al-Qahtani et al in Saudi Arabia (51.3\%), Goverwa et al in Zimbabwe $(32.8 \%),{ }^{42}$ Menanga et al in Cameroon (36.8\%), ${ }^{24}$ Khader et al among Jordanian adults $(32.9 \%){ }^{13}$ Mutua et al in Central Kenya (33.4\%), ${ }^{12}$ Animut et al at University of Gondar referral hospital, Ethiopia (50.4\%). ${ }^{16}$ Asgedom et al at Southwest Ethiopia (50.3\%), ${ }^{21}$ Teshome et al in Northwest Ethiopia (42.9\%), ${ }^{15}$ Lichisa et al in Adama, Ethiopia $(43.6 \%),{ }^{43}$ Horsa et al in Ethiopia $(26.2 \%),{ }^{9}$ Yazie et al in Ethiopia $(30.1 \%)^{2}$ and Gebremichael et al in Ethiopia $(47.5 \%){ }^{8}$ The higher rates of BP control in our study population might be due to the majority of the patients had regular follow-up visits at a dedicated follow-up clinic. However, the BP control rate was slightly lower than what that reported in the previous study by Abegaz et al in Ethiopia (89.6\%). ${ }^{1}$

The difference in the expertise of health care professionals involved in the management of HTN might have contributed to the discrepancy in the level of BP control. Moreover, in some of the studies, hypertensive patients on lifestyle modifications who were not taking antihypertensive drugs were included, ${ }^{39,44,45}$ which could have contributed to better control of BP than other studies. Additionally, the difference was probably due to a change in the criteria used to classify hypertensive patients as having uncontrolled and controlled BP. Most of the previous literature used JNC7 (which was used as a cutoff point $\geq 140 / 90$ for non-diabetic patients and $\geq 130 / 80$ for diabetic patients to say uncontrolled $\mathrm{BP})$ but the current study was conducted using the JNC8 guidelines. Also, the discrepancy might be due to racial, socio-cultural and behavioral differences among the population and healthcare services in the study settings. Additionally, the inconsistency could also be due to the differences in the anti-hypertensive medication adherence rate, the magnitude of co-morbidity, age of study participants, assessment scale and measurements of blood pressure, the utility of different guidelines, and type of drug therapy.

The mean age of the participants in the study was 59.4 \pm 10.4 years. This mean age was comparable to previous studies done in different areas, ${ }^{1,8,9,15,46}$ where the mean age of patients was in the $5^{\text {th }}$ decade. Unlike our study, previous studies showed that the majority of patients were above 60 years. $9,14,24,46,47$

The results of the multivariate analysis showed that patients with age $\geq 55$ years $(\mathrm{AOR}=0.38,95 \% \mathrm{CI}$ : $0.01-$ $0.92, \mathrm{p}=0.03$ ) were less likely to have UBP than those $<55$ years of age. A similar result was obtained from previous studies done in different settings. ${ }^{1,9,15,46,48}$ Better BP control in the elderly might be due to an increased prevalence of comorbidities, health care professionals could be more concerned about more frequent monitoring and earlier detection. Thus, older patients have more frequent visits to health facilities and have a higher chance of being informed of their BP and to be prescribed medications to control hypertension. As a result, they become adherent to the ordered medications. Additionally, denial of the existence of the disease or becoming busy with activities outside the home among young patients makes them forget to take their medications.

On the other hand, the results of other studies showed that patients aged younger than 60 years were more likely than older patients to have controlled BP. ${ }^{12,21,27,45,49-51}$ This was due to with increasing age, there will be increasing stiffness of the aorta and arterial walls which contribute to the observed high prevalence of HTN in the older group. $^{12,45,52}$ Thus, ongoing surveillance to determine trends in BP overage is necessary to provide a basis for evaluating and guiding public health interventions.

The duration of HTN diagnosis was also associated with uncontrolled BP in that patients with a diagnosis longer than 10 years were 2 times more likely to have UBP than those with a diagnosis of $<5$ years. The findings comply with the previous study conducted by Abebe et al in northwest Ethiopia. ${ }^{3}$ This might be due to the asymptomatic nature of the disease and a decrease in the healthseeking behavior of patients. On the contrary, the study by Animut et al reported that patients with a long duration of treatment have better BP control. ${ }^{16}$ This might be due to an increase in awareness and adherence to antihypertensive treatment as the patient stays on treatment for longer years. 
Medication adherence is the process by which a patient actively collaborates with health care professionals and takes their medications as prescribed. ${ }^{14}$ It is a dynamic process that changes over time and a key determinant to therapeutic success. It has also paramount importance for preventing the sequelae of associated morbidities and deaths. ${ }^{15}$ Among the hypertensive patients, insufficient adherence to drug therapy is one of the major reasons for poor BP control. ${ }^{14}$ Poor adherence attenuates optimum clinical benefits and reduces the overall effectiveness of health outcomes. ${ }^{19}$ According to a report from WHO, estimates of the extent to which patients adhere to pharmacotherapy for HTN vary between 43 to $88 \% .{ }^{53}$

The rate of adherence to antihypertensive medications in this study was $36 \%$ according to a self-reported measure of adherence using the 9 items HBMA rate. This level of adherence was lower than what was reported from Cameroon $(60 \%){ }^{24}$ Northwest Ethiopia $(77.3 \%)^{15}$ and southwest Ethiopia (60.5\%). ${ }^{21}$ However, the adherence rate in this study was closely similar to what was reported in Chile $(38.4 \%)^{27}$ and Nigeria (42.9\%). ${ }^{10}$ This might be attributed to the presence of comorbidities, increased number of medications and advanced age of patients which could significantly affect medication adherence. Additionally, in our setup, the majority of the patients were rural residents and the monthly income was very low, which might affect medication adherence. As the number of drugs the patients take increases; they may face a problem to take the right drug and dose at the right time.

The reported adherence to antihypertensive drugs was low in this study and interventions are needed to increase medication adherence to overcome challenges associated with UBP. The result of this study showed that nonadherent patients were three times more likely to have UBP than adherents $(\mathrm{AOR}=3.14,95 \% \mathrm{CI}: 1.35-10.76)$. This result was consistent with study findings from South Africa, ${ }^{41}$ Zimbabwe, ${ }^{42}$ Chile, ${ }^{27}$ Nigeria, ${ }^{54}$ Cameroon, ${ }^{24}$ Southern California ${ }^{55}$ and Ethiopia ${ }^{8,15,16,56}$ in which good adherence to antihypertensive medication was found to be protective against UBP. This congruency could be due to good adherence to antihypertensive medication is essential to control HTN and hence reduces BP. In light of this result, patients with suboptimal adherence, which includes failure to initiate pharmacotherapy, take medications as often as prescribed, and persisting on therapy long-term is a factor contributing to the poor control of BP. Thus, adherence in this population should be encouraged through educational intervention and the medication should be taken consistently even when a patient is feeling well.

Many chronic diseases are secondary causes of HTN so that controlling HTN among hypertensive patients with other chronic co-morbidities might be challenging. Among hypertensive patients in our study, $46.12 \%$ had written evidence of comorbidity and DM was the most frequent comorbid condition. This complies with previous studies, ${ }^{1,9,12,15,21,57}$ where DM was the most comorbid disease among hypertensive patients. The proportion of patients with co-morbidity was less than the study by Cheong et al where the majority $(87.5 \%)$ of the patients had one or more comorbidities. ${ }^{22}$ Similar to the previous study, ${ }^{1}$ in the present study, the coincidence of HTN with other comorbidities was not statistically associated with the occurrence of UBP. But other previous studies reported that comorbidities were significantly associated with BP control status. ${ }^{8,12,24,39,44,57}$ The discrepancy could be due to early detection, control and appropriate management of comorbid conditions. Additionally, the rate, extent, and type of comorbidities determine the impact of the significances.

The coincidence of co-morbidities such as DM, heart failure and chronic kidney disease (CKD) were frequently observed among hypertensive patients. These disorders are found to contribute to the progression of HTN by being involved in its pathogenesis, although no hypothesis has been able to elucidate the clear mechanism of the development of HTN from these comorbidities. ${ }^{1,19}$ The drug selection was also based on the presence of comorbidities commonly called "compelling indication" and targeting the lower cut point during the management process of HTN with the most appropriate regimen is associated with a low incidence of UBP and its complications. Hence, despite the occurrence of comorbidities, it could be reasonable to see tight BP control as long as the comorbid conditions are adequately managed. In addition to this, exposure of patients to medication to treat these comorbidities would probably increase their experience of complying with adherence, coping with side effects and dealing with polypharmacy. ${ }^{1}$

Anti-hypertensive medications lower and control high BP with different mechanisms including increasing vasodilatation, decreasing vasoconstriction, increasing urine output and blocking the sympathetic activation of the heart. ${ }^{58}$ In the present study, ACEIs, thiazides, and CCBs were the common antihypertensive drugs prescribed either in monotherapy, combination or both. Results resembling such pattern in the use of antihypertensive drugs were observed in different 
previous studies which reported that the most frequent group of antihypertensive medication was ACEIs. ${ }^{2,9}$ But the study by Cheong et $\mathrm{al}^{22}$ and Abegaz et $\mathrm{al}^{1}$ reported that the common types of antihypertensive medications were $\mathrm{CCB}$ and thiazides, respectively.

Antihypertensive prescription patterns vary from one country and hospital setup to another. The possible reasons for this disparity include patient characteristics, reimbursement policies, opinion leaders with conflicts of interests, traditions, domestic pharmaceutical production, and clinical practice guidelines. ${ }^{9}$ About half of the patients $(50.5 \%)$ received combination therapy. The higher prescription rate of combination therapy might be due to the hospital-based patients presented with the severe and more complicated HTN since they were referred from the lowerlevel health facilities. According to the Ethiopian guideline 2014, mono-therapy was only preferred if the target BP was achieved successfully by that particular antihypertensive agent. But if the target BP was not achieved with one agent, then poly-therapy should be introduced and low doses of two or more agents should be given. ${ }^{38}$

UBP among illiterate patients was 1.5 times more likely than those who had college and university education level. This was consistent with previous studies where low education level was found to have a negative association with BP control. ${ }^{22,39}$ The differences among educated and less-educated might be due to the different living styles, knowledge level, economic background and dietary habits of the patients. Another possible explanation might be the difference in information, communication strategies, clinical condition, and medication adherence level.

In this study, a significant association between sex and BP control status was observed. Accordingly, male patients were two times more likely to have UBP compared to female patients. This result was in line with previous studies ${ }^{10,15,22,27,39,44,45}$ where female patients were reported to have good odds of controlled BP than males. This might be due to males are usually loaded by activities outside the door which makes them tiring, exposes them to forget their drugs and finally make them difficult to control their BP.

Performing adequate physical activity has a strong and independent role in reducing BP. Epidemiological studies have also evidenced that physical activity results in significant BP and weight reduction. Consistent to this study, previous studies reported that patients who did physical exercise were more likely to have optimal BP control than patients with no physical activity. $8,15,16,21,59$ Although precise mechanisms have yet to be fully elucidated, available data have provided enough information to establish biologically plausible mechanisms for the relationship between physical exercise and HTN. Regular physical activity makes the heart stronger and can pump more blood with less effort. If the heart works less to pump, the force on the arteries reduces and thus lowering BP. Additionally, physical exercise also affects the reduction of systemic vascular resistance (vasoconstriction regulation), plasma norepinephrine, autonomic nervous system function, insulin sensitivity, and renin activities. ${ }^{16}$ Finally, the exercise also decreases high BP by decreasing body weight and increasing renal function. ${ }^{60}$

\section{Limitation of the Study}

First, it was a quantitative study with a cross-sectional design, it is not possible to identify risk factors (temporal relationship) but only show associations between clinical variables. Hence, it is difficult to confirm the causal- effect relationship between the dependent and predictor variables. The study involved patients being followed-up at a single hospital, not community-based, and thus may not reflect the real picture of the general population. Besides the study was conducted with a relatively small sample size, which may affect the generalizability of the findings. It is also important to note that other factors that could have been identified as limiting BP control, including race, cultural factors and other concomitant treatments were not analyzed.

Additionally, there might be recall and social desirability bias since the behavioral practice of the study participants was based on self-reports and the performance of this behavior was not observed and could not be confirmed. These may underestimate the effect of these variables on the dependent variable (biasing the measure of association towards the null). Finally, we did not also assess patients' knowledge of HTN and medication.

\section{Conclusion}

BP control was relatively optimum in the study set-up and achieved in about two-thirds of pharmacologically treated patients. About half of the participants had at least one comorbidity and the adherence level of patients to antihypertensive therapy was also low. The frequently used antihypertensive drug classes were ACEIs, thiazides, and CCBs. Male sex, lack of physical exercise, non-adherence to antihypertensive medications, and HTN diagnosis of $\geq 10$ years were identified as factors positively associated 
with UBP while age older than 55 years was negatively associated with UBP.

Recognizing the fact that controlling $\mathrm{BP}$ reduces CVD related morbidity and mortality as well as prevents costly interventions, we recommend policymakers in collaboration with stakeholders to develop strategies of lifestyle modifications, and adherence counseling to effectively control BP. Moreover, health care professionals and other stakeholders should promote to maximize patients' adherence to antihypertensive therapy and physical exercise. The Ministry of Health of Ethiopia should work to increase the level of understanding of the population towards the consequences of poor BP control and develop HTN management clinical practice guidelines. We also recommend NRH to devise strategies to provide education form hypertensive patients on dietary approaches to stop hypertension (DASH), medication adherence and involve dedicated senior physicians and clinical pharmacists at HTN clinic for better treatment and care of hypertensive patients. Additionally, we suggest researchers do further longitudinal studies that include physical and biochemical measurements to identify the most important variables associated with BP control, barriers to effective blood pressure control and possible interventions to improve treatment outcomes. Overall, we recommend better health education and care for the patients to improve the rate of BP control at the hospital.

\section{Abbreviations}

AOR, Adjusted odds ratio; BMI, Body max index; BP, Blood pressure; $\mathrm{CI}$, Confidence interval; $\mathrm{COR}$, Crude odds ratio; CVD, Cardiovascular disease; DASH, Dietary approaches to stop hypertension; DBP, diastolic blood pressure; HTN, Hypertension; HBMA, Hill-Bone Medication Adherence; HB-HBP, Hill-Bone Compliance to High Blood Pressure Therapy Scale; JNC, Joint National Commission; NCD, Non-communicable disease; SBP, Systolic blood pressure SSA, Sub-Saharan Africa; UBP, Uncontrolled blood pressure; WHO, World Health Organization.

\section{Data Sharing Statement}

The datasets used and/or analyzed during the current study are available from the corresponding author on reasonable request.

\section{Ethics and Consent Statement}

This study was conducted in accordance with the Declaration of Helsinki. Ethical clearance was obtained from the Institution Review Board (IRB) of the Institute of health sciences, Wollega University. The aim of the study was explained and verbal consent was obtained from responsible bodies and the chronic clinic of the NRH before the interview and reviews of the patient data. After a comprehensive explanation of the purpose, procedure, benefits, and risks of the study, written informed consent was obtained from the patients. Participant involvement in the study was voluntary and the right of participants to withdraw from the study at any time was secured. The protocol and the written consent was approved by the IRB of the Wollega University. All patient information was treated with the utmost confidentiality and no personal identifiers were included in the data abstraction format.

\section{Consent for Publication}

Not applicable. No individual personal details, images or videos are being used in this study.

\section{Acknowledgments}

The authors would like to acknowledge Wollega University for logistic support. We are also grateful to supervisors and data collectors. Our appreciation also goes to the chronic illness treatment clinic staff of NRH for their kind support during the data collection. Finally, we would like to heartfelt thanks to the study participants for their cooperation in the provision of their information and without whom the research would not have been completed.

\section{Author Contributions}

All authors made substantial contributions to conception and design, acquisition of data, analysis and interpretation of data, drafting the manuscript, revising the manuscript critically, read and approve the final draft of the manuscript for submission, gave final approval of the manuscript version to be published and agreed to be accountable for every step of the work.

\section{Disclosure}

The authors declare that they have no competing interests.

\section{References}

1. Abegaz TM, Abdela OA, Bhagavathula AS, Teni FS. Magnitude and determinants of uncontrolled blood pressure among hypertensive patients in Ethiopia: hospital-based observational study. Pharm Pract (Granada). 2018;16(2):2. doi:10.18549/PharmPract.2018.02.1173

2. Yazie D, Shibeshi W, Alebachew M, Berha A. Assessment of blood pressure control among hypertensive patients in Zewditu Memorial Hospital, Addis Ababa, Ethiopia: a cross-sectional study. J Bioanal Biomed. 2018;10(03):80-87. doi:10.4172/1948-593X.1000210 
3. Abebe SM, Berhane Y, Worku A, Getachew A. Prevalence and associated factors of hypertension: a crossectional community based study in Northwest Ethiopia. PLoS One. 2015;10(4):e0125210. doi:10.1371/journal.pone. 0125210

4. Dalal S, Beunza JJ, Volmink J, et al. Non-communicable diseases in sub-Saharan Africa: what we know now. Int $J$ Epidemiol. 2011;40 (4):885-901. doi:10.1093/ije/dyr050

5. Bhusal A, Jadhav PR, Deshmukh YA. Assessment of medication adherence among hypertensive patients: a cross-sectional study. Int J Basic Clin Pharmacol. 2016;5(4):1606. doi:10.18203/23192003.ijbcp20162480

6. Kearney PM, Whelton M, Reynolds K, Muntner P, Whelton PK, He J. Global burden of hypertension: analysis of worldwide data. Lancet (London, England). 2005;365(9455):217-223. doi:10.1016/ S0140-6736(05)17741-1

7. Kale S, Patil A, Mandlecha R. Compliance and adverse drug effects of antihypertensives in rural India. J Clin Diagn Res. 2011;5 (4):775-779.

8. Gebremichael GB, Berhe KK, Zemichael TM. Uncontrolled hypertension and associated factors among adult hypertensive patients in Ayder comprehensive specialized hospital, Tigray, Ethiopia, 2018. BMC Cardiovasc Disord. 2019;19(1):121. doi:10.1186/s12872-019-1091-6

9. Horsa BA, Tadesse Y, Engidawork E. Assessment of hypertension control and factors associated with the control among hypertensive patients attending at Zewditu Memorial Hospital: a cross sectional study. BMC Res Notes. 2019;12(1):152. doi:10.1186/s13104-019-4173-8

10. Cordero A, Bertomeu-Martínez V, Mazón P, et al. Factors associated with uncontrolled hypertension in patients with and without cardiovascular disease. Rev Esp Cardiol. 2011;64(7):587-593. doi:10.1016/ j.rec.2011.03.007

11. Organization WH. A Global Brief on Hypertension: Silent Killer, Global Public Health Crisis: World Health Day 2013. Geneva: Switzerland; 2013.

12. Mutua EM, Gitonga MM, Mbuthia B, Muiruri N, Cheptum JJ, Maingi T. Level of blood pressure control among hypertensive patients on follow-up in a regional referral hospital in Central Kenya. Pan Afr Med J. 2014;18:278. doi:10.11604/pamj.2014.18. 278.4308

13. Khader Y, Batieha A, Jaddou H, et al. Hypertension in Jordan: prevalence, awareness, control, and its associated factors. Int J Hypertens. 2019;2019.

14. Al-Qahtani AM. Prevalence and determinants of blood pressure control among hypertensive patients in primary care centers, Najran, Saudi Arabia. Biomed Pharmacol J. 2018;11(2):821-825. doi:10.13 $005 / \mathrm{bpj} / 1437$

15. Teshome DF, Bekele KB, Habitu YA, Gelagay AA. Medication adherence and its associated factors among hypertensive patients attending the Debre Tabor General Hospital, northwest Ethiopia. Integr Blood Press Control. 2017;10:1. doi:10.2147/IBPC.S128914

16. Animut Y, Assefa AT, Lemma DG. Blood pressure control status and associated factors among adult hypertensive patients on outpatient follow-up at University of Gondar Referral Hospital, northwest Ethiopia: a retrospective follow-up study. Integr Blood Press Control. 2018;11:37. doi:10.2147/IBPC.S150628

17. Williams B, Poulter NR, Brown MJ, et al. British Hypertension Society guidelines for hypertension management 2004 (BHS-IV): summary. BMJ (Clinical Research Ed.). 2004;328(7440):634-640. doi:10.1136/bmj.328.7440.634

18. Whitworth JA. World Health Organization (WHO)/International Society of Hypertension (ISH) statement on management of hypertension. J Hypertens. 2003;21(11):1983-1992.

19. Chobanian A, Bakris G, Black H, et al. And the national high blood pressure education program coordinating committee on prevention, detection, evaluation, and treatment of high blood pressure. the JNC 7 report. JAMA. 2003;289(19):2534-2573. doi:10.1001/jama.289.19. 2560
20. Weber MA, Schiffrin EL, White WB, et al. Clinical practice guidelines for the management of hypertension in the community: a statement by the American Society of Hypertension and the International Society of Hypertension. J Clin Hypertens. 2014;16 (1):14-26. doi:10.1111/jch.12237

21. Asgedom SW, Gudina EK, Desse TA, Boltze J. Assessment of blood pressure control among hypertensive patients in Southwest Ethiopia. PLoS One. 2016;11(11):e0166432. doi:10.1371/journal.pone.0166 432

22. Cheong A, Sazlina S-G, Tong S, Azah AS, Salmiah S. Poor blood pressure control and its associated factors among older people with hypertension: a cross-sectional study in six public primary care clinics in Malaysia. Malaysian Family Physician off J Acad Family Physicians Malaysia. 2015;10(1):19.

23. Twagirumukiza M, De Bacquer D, Kips JG, de Backer G, Vander Stichele R, Van Bortel LM. Current and projected prevalence of arterial hypertension in sub-Saharan Africa by sex, age and habitat: an estimate from population studies. $J$ Hypertens. 2011;29 (7):1243-1252. doi:10.1097/HJH.0b013e328346995d

24. Menanga A, Edie S, Nkoke C, et al. Factors associated with blood pressure control amongst adults with hypertension in Yaounde, Cameroon: a cross-sectional study. Cardiovasc Diagn Ther. 2016;6 (5):439. doi:10.21037/cdt.2016.04.03

25. Ogah OS, Rayner BL. Recent advances in hypertension in sub-Saharan Africa. Heart. 2013;99(19):1390-1397. doi:10.1136/ heartjnl-2012-303227

26. World Health Organization. Global Status Report on Noncommunicable Diseases 2014. Geneva: Switzerland; 2014.

27. Sandoval D, Nazzal C, Romero T. Clinical, socioeconomic, and psychosocial factors associated with blood pressure control and adherence: results from a multidisciplinary cardiovascular national program providing universal coverage in a developing country. Int J Hypertens. 2018;2018:1-10. doi:10.1155/2018/5634352

28. World Health Organization. WHO STEPS instrument (core and expanded). The WHO STEPwise approach to noncommunicable disease risk factor surveillance (STEPS). Geneva, Switzerland: The World Health Organization; 2016. Available from: https://www. who.int/ncds/surveillance/steps/STEPS_Manual.pdf?ua=1. Accessed April 4, 2018.

29. WHO STEPS Instrument (Core and Expanded). The WHO STEPwise Approach to Chronic Disease Risk Factor Surveillance (STEPS). Geneva, Switzerland: World Health Organization; 2008. Available from: https://www.who.int/ncds/surveillance/steps/STEPS_ Instrument_v2.1.pdf. Accessed April 4, 2018.

30. Liz S. New AHA recommendations for blood pressure measurement: american heart association practice guidelines. Am Fam Physician. 2005;72(7):1391-1398.

31. James PA, Oparil S, Carter BL, et al. Evidence-based guideline for the management of high blood pressure in adults: report from the panel members appointed to the Eighth Joint National Committee (JNC 8). JAMA. 2014;311(5):507-520. doi:10.1001/jama.2013.284 427

32. Alexander M, Tekawa I, Hunkeler E, et al. Evaluating hypertension control in a managed care setting. Arch Intern Med. 1999;159 (22):2673-2677. doi:10.1001/archinte.159.22.2673

33. Fleisher LA, Beckman JA, Brown KA, et al. ACCF/AHA focused update on perioperative beta blockade incorporated into the ACC/ AHA 2007 guidelines on perioperative cardiovascular evaluation and care for noncardiac surgery. Circ. 2009;120(21):e169-e276. doi:10.1161/CIRCULATIONAHA.109.192690

34. Lam WY, Fresco P. Medication adherence measures: an overview. Biomed Res Int. 2015;2015:12. doi:10.1155/2015/217047

35. Song Y, Han HR, Song HJ, Nam S, Nguyen T, Kim MT. Psychometric evaluation of hill-bone medication adherence subscale. Asian Nurs Res. 2011;5(3):183-188. doi:10.1016/j. anr.2011.09.007 
36. Kim MT, Hill MN, Bone LR, Levine DM. Development and testing of the hill-bone compliance to high blood pressure therapy scale. Prog Cardiovasc Nurs. 2000;15(3):90-96. doi:10.1111/j.17517117.2000.tb00211.x

37. World Health Organization. Global Database on Body Mass Index. Geneva, Switzerland: WHO;2015.

38. Ethiopian Medicine. Food and Healthcare Administration And, Control Authority (EFMHACA). Standard Treatment Guidelines for General Hospitals.Ethiopia. 3rd ed. 2014. Available from: http:// apps.who.int/medicinedocs/documents/s21694en/s21694en.pdf. Accessed October 22, 2019.

39. Sandoval D, Bravo M, Koch E, et al. Overcoming barriers in the management of hypertension: the experience of the cardiovascular health program in Chilean primary health care centers. Int J Hypertens. 2012;2012:1-8. doi:10.1155/2012/405892

40. Gu Q, Burt VL, Dillon CF, Yoon S. Trends in antihypertensive medication use and blood pressure control among United States adults with hypertension: the national health and nutrition examination survey, 2001 to 2010. Circ. 2012;126(17):2105-2114. doi:10.1161/CIRCULATIONAHA.112.096156

41. Onwukwe SC, Omole OB. Drug therapy, lifestyle modification and blood pressure control in a primary care facility, south of Johannesburg, South Africa: an audit of hypertension management. $S$ Afr Fam Pract. 2012;54(2):156-161. doi:10.1080/20786204. 2012.10874196

42. Goverwa TP, Masuka N, Tshimanga M, et al. Uncontrolled hypertension among hypertensive patients on treatment in Lupane District, Zimbabwe, 2012. BMC Res Notes. 2014;7(1):703. doi:10.1186/17560500-7-703

43. Lichisa G, Tegegne G, Gelaw B, Defersha A, Woldu M, Linjesa J. Blood pressure control and its contributing factor among ambulatory hypertensive patients in Adama Hospital medical college, East Shoa, Adama, Ethiopia. Int J Pharm Biol Sci Res Dev. 2014;2(7).

44. Shelley D, Tseng T-Y, Andrews H, et al. Predictors of blood pressure control among hypertensives in community health centers. Am J Hypertens. 2011;24(12):1318-1323. doi:10.1038/ajh.2011.154

45. Ornstein SM, Nietert PJ, Dickerson LM. Hypertension management and control in primary care: a study of 20 practices in 14 states. Pharmacother. 2004;24(4):500-507. doi:10.1592/phco.24.5.500.33 359

46. Silva CS, Paes NA, Figueiredo T, Cardoso MAA, ATMCd S, Araújo J. Blood pressure control and adherence/attachment in hypertensive users of primary healthcare. Rev ESC Enferm USP. 2013;47 (3):584-590. doi:10.1590/S0080-623420130000300009

47. Woldu MA, Shiferaw DF, Lenjisa JL, Tegegne GT, Tesafye G, Dinsa H. Antihypertensive medications pattern and their effect in blood pressure control in patients attending Bishoftu general hospital ambulatory ward, Debrezeit (Bishoftu), Ethiopia. World J Pharm Sci. 2014;2(10):1198-1205.
48. Wang H, Zhang X, Zhang J, et al. Factors associated with prevalence, awareness, treatment and control of hypertension among adults in Southern China: a community-based, cross-sectional survey. PLoS One. 2013;8(5):e62469. doi:10.1371/journal.pone.0062469

49. Tesfaye B, Haile D, Lake B, Belachew T, Tesfaye T, Abera H. Uncontrolled hypertension and associated factors among adult hypertensive patients on follow-up at Jimma University Teaching and Specialized Hospital: cross-sectional study. Res Rep Clin Cardiol. 2017;8:21. doi:10.2147/RRCC.S132126

50. Kanungo S, Mahapatra T, Bhowmik K, et al. Patterns and predictors of undiagnosed and uncontrolled hypertension: observations from a poor-resource setting. J Hum Hypertens. 2017;31(1):56. doi:10.1038/ jhh. 2016.30

51. De MM, Lima MJ, Silva AO, Alcântara P, Ramalhinho V, Carmona J. Prevalence, awareness, treatment and control of hypertension in Portugal. The PAP study. Rev Port Cardiol. 2007;26(1):21-39.

52. Hyman DJ, Pavlik VN. Characteristics of patients with uncontrolled hypertension in the United States. $N$ Engl J Med. 2001;345 (7):479-486. doi:10.1056/NEJMoa010273

53. World Health Organization. Adherence to Long-Term Therapies: Evidence for Action. Geneva: Switzerland; 2003.

54. Iloh GU, Ofoedu JN, Njoku PU, Amadi AN, Godswill-Uko EU. Medication adherence and blood pressure control amongst adults with primary hypertension attending a tertiary hospital primary care clinic in Eastern Nigeria. Afr J Prim Health Care Fam Med. 2013;5 (1). doi:10.4102/phcfm.v5i1.446

55. Elperin DT, Pelter MA, Deamer RL, Burchette RJ. A large cohort study evaluating risk factors associated with uncontrolled hypertension. J Clin Hypertens. 2014;16(2):149-154. doi:10.1111/ jch.12259

56. Abdu O, Diro E, Abera Balcha MA, et al. Blood pressure control among hypertensive patients in University of Gondar Hospital, Northwest Ethiopia: a cross sectional study. Hypertens. 2017;140 (1):6.

57. Olomu AB, Gourineni V, Huang JL, et al. Rate and predictors of blood pressure control in a federal qualified health center in Michigan: a huge concern? J Clin Hypertens. 2013;15(4):254-263. doi:10.1111/jch.12067

58. Bell K, Twiggs J, Olin BR, Date IR. Hypertension: the silent killer: updated JNC-8 guideline recommendations. Alabama Pharm Assoc. 2015;334:4222.

59. Whelton PK, Carey RM, Aronow WS, et al. ACC/AHA/AAPA/ABC/ ACPM/AGS/APhA/ASH/ASPC/NMA/PCNA guideline for the prevention, detection, evaluation, and management of high blood pressure in adults: a report of the American College of Cardiology/ American Heart Association task force on clinical practice Guidelines. J Am Coll Cardiol. 2017;2017:24430.

60. Diaz KM, Shimbo D. Physical activity and the prevention of hypertension. Curr Hypertens Rep. 2013;15(6):659-668. doi:10.10 07/s11906-013-0386-8
Integrated Blood Pressure Control

\section{Publish your work in this journal}

Integrated Blood Pressure Control is an international, peer-reviewed open-access journal focusing on the integrated approach to managing hypertension and risk reduction. Treating the patient and comorbidities together with diet and lifestyle modification and optimizing healthcare resources through a multidisciplinary team approach constitute key features of the journal. This journal is indexed on
American Chemical Society's Chemical Abstracts Service (CAS) The manuscript management system is completely online and includes a very quick and fair peer-review system, which is all easy to use. Visit http://www.dovepress.com/testimonials.php to read real quotes from published authors. 